\title{
Family Stress and The Risk of Cardiovascular Diseases in Working-Age Population 25-64 Years (WHO program MONICA-Psychosocial)
}

\author{
Gafarov VV ${ }^{*}, 2$, Gromova EA ${ }^{1,2}$, Panov DO ${ }^{1,2}$, Gagulin IV ${ }^{1,2}$ and Gafarova $\mathrm{AV}^{1,2}$ \\ ${ }^{1}$ Institute of Internal and Preventive Medicine - branch of \\ Institute of Cytology and Genetics RAS, Novosibirsk \\ ${ }^{2}$ Collaborative laboratory of Cardiovascular Diseases \\ Epidemiology, Novosibirsk \\ *Corresponding authors \\ Valery V Gafarov, Institute of Internal and Preventive Medicine - branch of \\ Institute of Cytology and Genetics RAS, Novosibirsk. \\ Submitted: 24 March2021; Accepted: 30 March 2021;Published: 05 Apr 2021
}

Citation: Gafarov VV, Gromova EA, Panov DO, Gagulin IV, Gafarova AV (2021) Family Stress and The Risk of Cardiovascular Diseases in Working-Age Population 25-64 Years (WHO program MONICA-Psychosocial). Medical \& Clinical Research 6(4): 542-545.

\begin{abstract}
Purpose: To determine the influence of family stress on the risk of cardiovascular diseases (myocardial infarction and stroke) in an open population aged 25-64 years in Russia / Siberia.

Methods: Within the framework of the III screening of WHO's MONICA-psychosocial program, a random representative sample of the population of both sexes of 25-64 years of Novosibirsk in 1994 (men $n=657$, mean age 44,3 $\pm 0,4 y$, response 82.1\%, women: $n=689$, mean age 45,4 $\pm 0,4 y$, response $72.5 \%$ ) was examined. The screening included: socio-demographic data, the definition of the family stress. New-onset cases of MI and stroke in women - 15 and 35 cases and in men - 30 and 22 cases, respectively detected in the cohort over follow-up period in frame of budgetary theme № AAAA-A17-117112850280-2.
\end{abstract}

\begin{abstract}
Results: In the open population aged of 25-64 years the prevalence of high family stress was higher in men (31.5\%) than women (20.9\%). The risk of myocardial infarction in men and women experiencing stressful situations in the family was 5.9 and 5.58-fold higher, respectively over 16-year period. The most significant risk factors for the development of myocardial infarction were divorce $(H R=3.9)$ and widowhood $(H R=6.3)$. The risk of developing a stroke was 3.45-fold higher in men and 3.52-fold higher in women with family stress. The risk of developing stroke was higher among those with high school and elementary education levels, both in men $(H R=3.9$ and $H R=6.3)$ and women $(H R=2.87$ and $H R=3.33)$.
\end{abstract}

Conclusion: Stress in the family is more common in men within the working-age population. Family stress increases the risk of developing both myocardial infarction and stroke among men and women.

Keywords: Men, Women, Stress at Home, Relative Risk, Myocardial Infarction, Stroke

\section{Introduction}

Cardiovascular disease remains the leading cause of the burden of disease globally, which underpins the continuing need to identify new additional targets for prevention [1]. To reduce the burden of cardiovascular diseases in addition to identifying generally recognized risk factors for CVD it is necessary to determine a target group in the population undergoing high risk of future cardiovascular events which need timely preventive programs [2]. Although $80 \%$ of CVD risk can be predicted based on well-known CVD risk factors such as old age, male gender, hypertension, hyperlipidemia, smoking and diabetes mellitus the determinants for another $20 \%$ of risk remain unclear [3]. The unconventional risk factors that may be associated with CVD include psychosocial factors in particularly the family stress [4]. A favorable psychological climate in the family leads to a decrease in the risk of developing both myocardial infarction $[5,6]$ and stroke [7]. There are studies that have not found the effect of stressful situations in the family on the risk of future CVD $[8,9]$. In addition, there are studies that show certain gender differences in the effect of family stress on CVD risk [10]. In view of the fragmentation of the results and different interpretations of problems in the family, as well as probable gender characteristics, the purpose of our study was to study the prognostic effect of stress in the family on the risk of CVD (myocardial infarction and stroke) in an open population aged of 25-64 years in Novosibirsk.

\section{Methods}

Within the framework of the III screening of the WHO MONICA-

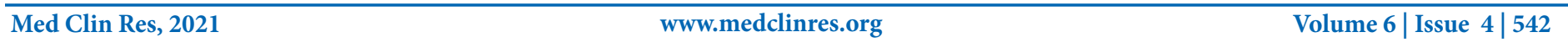


psychosocial program (Monitoring trends in morbidity and mortality from cardiovascular diseases and their determining factors) [11] a random representative sample of general population 25-64 years in the of the city district in Novosibirsk was examined in 1994. (men $-\mathrm{n}=657$, mean age $-44.3 \pm 0.4$ years, response $-82.1 \%$; women $\mathrm{n}=689$, mean age $-45.4+-0.4$ years, response $72.5 \%$ ). The sample was formed according to the requirements of the WHO MONICA - psychosocial protocol [11].
The screening examination program included the following sections:

1) registration of socio-demographic data was carried out according to the standard epidemiological protocol of the WHO MONICApsychosocial program: identification number, place of residence, full name, date of birth, date of registration. Gender: 1 - male, 2 - female. The distribution by age group is presented in Table 1. Marital status (Table 2), education level (Table 3), professional level (Table 4) were taken into account.

Table 1: Distribution on age groups in population aged of 25-64 years (III screening, 1994)

\begin{tabular}{|c|c|c|c|c|c|c|c|c|c|}
\hline \multirow[t]{3}{*}{$\operatorname{sex}$} & \multicolumn{8}{|c|}{ age groups } & \multirow[t]{3}{*}{ Total } \\
\hline & \multicolumn{2}{|c|}{ 25-34 years } & \multicolumn{2}{|c|}{$35-44$ years } & \multicolumn{2}{|c|}{ 45-54 years } & \multicolumn{2}{|c|}{ 55-64 years } & \\
\hline & $\mathbf{n}$ & $\%$ & $\mathbf{n}$ & $\%$ & $\mathbf{n}$ & $\%$ & $\mathbf{n}$ & $\%$ & \\
\hline male & 169 & 50.8 & 136 & 45.9 & 177 & 47.7 & 175 & 50.6 & 657 \\
\hline female & 164 & 49.2 & 160 & 54.1 & 194 & 52.3 & 171 & 49.4 & 689 \\
\hline Total & 333 & 100 & 296 & 100 & 371 & 100 & 346 & 100 & 1346 \\
\hline
\end{tabular}

$\chi^{2}=2.087 \mathrm{df}=3 \mathrm{p}=0.555$

Table 2: Distribution on marital status in population aged of 25-64 years (III screening, 1994)

\begin{tabular}{|c|c|c|c|c|c|c|c|c|c|}
\hline \multirow[t]{3}{*}{$\operatorname{sex}$} & \multicolumn{8}{|c|}{ marital statu } & \multirow[t]{3}{*}{ Total } \\
\hline & \multicolumn{2}{|c|}{ Never Married } & \multicolumn{2}{|c|}{ Married } & \multicolumn{2}{|c|}{ Divorced } & \multicolumn{2}{|c|}{ Widowed } & \\
\hline & $\mathbf{n}$ & $\%$ & $\mathbf{n}$ & $\%$ & $\mathbf{n}$ & $\%$ & $\mathbf{n}$ & $\%$ & \\
\hline male & 45 & 51.1 & 559 & 51.7 & 40 & 35.7 & 13 & 20 & 657 \\
\hline female & 43 & 48.9 & 522 & 48.3 & 72 & 64.3 & 52 & 80 & 689 \\
\hline Total & 88 & 100 & 1081 & 100 & 112 & 100 & 65 & 100 & 1346 \\
\hline
\end{tabular}

$\chi^{2}=33.113 \mathrm{df}=3 \mathrm{p}=0.0001$

Table 3: Distribution on educational degree in population aged of 25-64 years (III screening, 1994)

\begin{tabular}{|c|c|c|c|c|c|c|c|c|c|}
\hline \multirow[t]{3}{*}{ sex } & \multicolumn{8}{|c|}{ educational degree } & \multirow[t]{3}{*}{ Total } \\
\hline & \multicolumn{2}{|c|}{ University } & \multicolumn{2}{|c|}{ College } & \multicolumn{2}{|c|}{ High school } & \multicolumn{2}{|c|}{ Elementary/primary } & \\
\hline & $\mathbf{n}$ & $\%$ & n & $\%$ & $\mathbf{n}$ & $\%$ & n & $\%$ & \\
\hline male & 186 & 49.2 & 178 & 44.3 & 150 & 49.2 & 143 & 55.6 & 657 \\
\hline female & 192 & 50.8 & 224 & 55.7 & 155 & 50.8 & 114 & 44.4 & 685 \\
\hline Total & 378 & 100 & 402 & 100 & 305 & 100 & 257 & 100 & 1342 \\
\hline
\end{tabular}

$\chi^{2}=8.133 \mathrm{df}=3 \mathrm{p}=0.043$

Table 4: Distribution on occupational status in population aged of 25-64 years (III screening, 1994)

\begin{tabular}{|c|c|c|c|c|c|c|c|c|c|c|c|c|c|c|c|c|c|c|c|}
\hline \multirow[t]{3}{*}{$\operatorname{sex}$} & \multicolumn{18}{|c|}{ occupational status } & \multirow[t]{3}{*}{ Total } \\
\hline & \multicolumn{2}{|c|}{ TM } & \multicolumn{2}{|c|}{ MM } & \multicolumn{2}{|c|}{ Manag } & \multicolumn{2}{|c|}{ Engineers } & \multicolumn{2}{|c|}{ WHPL } & \multicolumn{2}{|c|}{ WAPL } & \multicolumn{2}{|c|}{ WLPL } & \multicolumn{2}{|c|}{ Students } & \multicolumn{2}{|c|}{ Retired } & \\
\hline & $\mathbf{n}$ & $\%$ & $n$ & $\%$ & $\mathbf{n}$ & $\%$ & $\mathrm{n}$ & $\%$ & $\mathbf{n}$ & $\%$ & $\mathbf{n}$ & $\%$ & $\mathrm{n}$ & $\%$ & $\mathbf{n}$ & $\%$ & $\mathrm{n}$ & $\%$ & \\
\hline M & 28 & 84.8 & 55 & 55.6 & 65 & 50.8 & 84 & 42 & 144 & 88.9 & 167 & 63.3 & 21 & 17.1 & 9 & 81.8 & 84 & 34.7 & 657 \\
\hline $\mathrm{F}$ & 5 & 15.2 & 44 & 44.4 & 63 & 49.2 & 116 & 58 & 18 & 11.1 & 97 & 36.7 & 102 & 82.9 & 2 & 18.2 & 158 & 65.3 & 605 \\
\hline Total & 33 & 100 & 99 & 100 & 128 & 100 & 200 & 100 & 162 & 100 & 264 & 100 & 123 & 100 & 11 & 100 & 242 & 100 & 1262 \\
\hline
\end{tabular}

$\chi^{2}=238.16 \mathrm{df}=8 \mathrm{p}=0.001$ 
TM - Top Managers

MM - Middle Managers

Manag - Managers

WHPL - Workers of heavy physical labor

WAPL - workers of average physical labor

WLPL - workers of light physical labor

2) Testing according to psychosocial methods: to assess the level of stress in the family, the questionnaire "Knowledge and attitude to one's health" was proposed. The subjects were asked to independently answer the questions of the scales according to the instructions given in the questionnaire. The analyzed level of the risk factor was taken as its value in the original study and did not take into account the contribution of time dynamics. The methods were strictly standardized and corresponded to the requirements of the protocol of the WHO MONICA program - psychosocial [11]. Processing of the material under the WHO MONICA - psychosocial program was carried out at the MONICA Information Collection Center in Helsinki (Finland). Quality control was carried out in MONICA quality control centers: Dundee (Scotland), Prague (Czech Republic), Budapest (Hungary). The presented results were found to be satisfactory [11].

All women and men with identified cardiovascular pathology (ischemic heart disease, vascular diseases of the brain, arterial hypertension, myocardial infarction, diabetes mellitus) that occurred before or during the screening period were excluded from the study. The analysis included 384 women and 190 men age 25-64 years at baseline. The prospective follow-up period for participants was 16 years.
The study identified the following "endpoints": new-onset cases of myocardial infarction (MI), stroke. Registration of all cases of MI was carried out on the basis of the WHO program "Registry of acute myocardial infarction". Sources used to identify cases of stroke: annual survey of individuals in the population cohort, medical records, inpatient discharge reports, district clinics, death certificates, interviews with relatives, autopsy and forensic reports. During the observation period in frame of budgetary theme № AAAA-A17-117112850280-2, the cohort revealed 15 cases of new-onset myocardial infarction in women and 30 in men, and 35 cases of new-onset stroke in women and 22 in men.

Statistical analysis was performed using the SPSS software package version 11.5 [12]. To check the statistical significance of differences between groups, we used: Pearson's chi-square test $\chi 2$. To assess the risk ratio - hazard ratio (HR) and its $95 \% \mathrm{CI}$ (confidence interval) (minimum-maximum), taking into account different control times, we used the univariate single-factor Cox-regression and multivariate proportional-hazards regression model [13]. Reliability in all types of analysis was accepted at a significance level of $\mathrm{p} \leq 0.05$.

\section{Results}

In the open population of 25-64 years in Novosibirsk both a high level (31.5\% and $20.9 \%$, respectively) and an average level (50.3\% and $48.2 \%$, respectively) of stress in the family were higher among men than among women $(\chi 2=29.638 \mathrm{df}=2 \mathrm{p}=0.001)$. Indicators of a high level of stress in the family were more common in men aged of 55-64 years $(39.3 \%)(\chi 2=19.744 \mathrm{df}=2 \mathrm{p}=0.001)$ and in women at the age of $45-54$ years $(22.9 \%)\left(\chi^{2}=7.659 \mathrm{df}=2 \mathrm{p}=\right.$ 0.022 ) as presented in table 5 .

Table 5: Family stress in population 25-64 years (III screening, 1994)

\begin{tabular}{|c|c|c|c|c|c|c|c|c|c|c|c|c|c|c|c|c|c|c|c|c|}
\hline \multirow{3}{*}{$\begin{array}{l}\text { Family } \\
\text { stress }\end{array}$} & \multicolumn{4}{|c|}{$25-34$} & \multicolumn{4}{|c|}{$35-44$} & \multicolumn{4}{|c|}{$45-54$} & \multicolumn{4}{|c|}{$55-64$} & \multicolumn{4}{|c|}{$25-64$} \\
\hline & \multicolumn{2}{|c|}{ M } & \multicolumn{2}{|c|}{$\mathbf{F}$} & \multicolumn{2}{|c|}{ M } & \multicolumn{2}{|c|}{$\mathbf{F}$} & \multicolumn{2}{|c|}{ M } & \multicolumn{2}{|c|}{$\mathbf{F}$} & \multicolumn{2}{|c|}{ M } & \multicolumn{2}{|c|}{$\mathbf{F}$} & \multicolumn{2}{|c|}{ M } & \multicolumn{2}{|c|}{$\mathbf{F}$} \\
\hline & $\mathbf{N}$ & $\%$ & $\mathbf{N}$ & $\%$ & $\mathbf{N}$ & $\%$ & $\mathbf{N}$ & $\%$ & $\mathbf{N}$ & $\%$ & $\mathbf{N}$ & $\%$ & $\mathbf{N}$ & $\%$ & $\mathbf{N}$ & $\%$ & $\mathbf{N}$ & $\%$ & $\mathbf{N}$ & $\%$ \\
\hline Low & 32 & 20.8 & 36 & 28.6 & 34 & 20.9 & 34 & 30.4 & 24 & 18.9 & 46 & 32.9 & 18 & 12 & 39 & 31.5 & 108 & 18.2 & 155 & 30.9 \\
\hline Moderate & 80 & 51.9 & 61 & 48.4 & 86 & 52.8 & 60 & 53.4 & 61 & 48 & 62 & 44.3 & 73 & 48.7 & 59 & 47.6 & 300 & 50.3 & 242 & 48.2 \\
\hline High & 42 & 27.3 & 29 & 23 & 43 & 26.4 & 18 & 16.1 & 42 & 33.1 & 32 & 22.9 & 59 & 39.3 & 26 & 21 & 186 & 31.5 & 105 & 20.9 \\
\hline \multirow[t]{2}{*}{ Total } & 154 & 100 & 126 & 100 & 163 & 100 & 112 & 100 & 127 & 100 & 140 & 100 & 150 & 100 & 124 & 100 & 594 & 100 & 502 & 100 \\
\hline & \multicolumn{4}{|c|}{$\begin{array}{c}\chi^{2}=2.400 \mathrm{df}=2 ; \quad \mathrm{P}= \\
0.301\end{array}$} & \multicolumn{4}{|c|}{$\begin{array}{c}\chi^{2}=5.611 \mathrm{df}=2 \mathrm{P} \\
=0.06\end{array}$} & \multicolumn{4}{|c|}{$\begin{array}{c}\chi^{2}=7.659 \mathrm{df}=2 \mathrm{P} \\
=0.022\end{array}$} & \multicolumn{4}{|c|}{$\begin{array}{c}\chi^{2}=19.744 \mathrm{df}=2 \\
\mathrm{P}=0.001\end{array}$} & \multicolumn{4}{|c|}{$\begin{array}{c}\chi^{2}=29.638 \mathrm{df}=2 \\
P=0.001\end{array}$} \\
\hline
\end{tabular}

The highest level of family stress in our population was experienced by widowed men $(30 \%)$ and widowed women $(22.5 \%)(\chi 2=6792 \mathrm{df}=$ 2; $\mathrm{p}=003$ ) (Table 6). 
Table 6: Family stress and marital status in population 25-64 years (III screening, 1994)

\begin{tabular}{|c|c|c|c|c|c|c|c|c|c|c|c|c|c|c|c|c|}
\hline \multirow[t]{3}{*}{ Family stress } & \multicolumn{4}{|c|}{ Never Married } & \multicolumn{4}{|c|}{ Married } & \multicolumn{4}{|c|}{ Divorced } & \multicolumn{4}{|c|}{ Widowed } \\
\hline & \multicolumn{2}{|c|}{ M } & \multicolumn{2}{|c|}{$\mathbf{F}$} & \multicolumn{2}{|c|}{$\mathbf{M}$} & \multicolumn{2}{|c|}{$\mathbf{F}$} & \multicolumn{2}{|c|}{ M } & \multicolumn{2}{|c|}{$\mathbf{F}$} & \multicolumn{2}{|c|}{ M } & \multicolumn{2}{|c|}{$\mathbf{F}$} \\
\hline & $\mathbf{N}$ & $\%$ & $\mathbf{N}$ & $\%$ & $\mathbf{N}$ & $\%$ & $\mathbf{N}$ & $\%$ & $\mathbf{N}$ & $\%$ & $\mathbf{N}$ & $\%$ & $\mathbf{N}$ & $\%$ & $\mathbf{N}$ & $\%$ \\
\hline Low & 9 & 23.1 & 12 & 37.5 & 162 & 31.7 & 114 & 29.8 & 8 & 9.4 & 14 & 29.8 & 3 & 30 & 14 & 35 \\
\hline Moderate & 17 & 43.6 & 9 & 28.1 & 256 & 50.1 & 194 & 50.8 & 21 & 65.6 & 22 & 46.8 & 4 & 40 & 17 & 42.5 \\
\hline High & 13 & 33.3 & 11 & 34.4 & 93 & 18.2 & 74 & 19.4 & 3 & 25 & 11 & 23.4 & 3 & 30 & 9 & 22.5 \\
\hline \multirow[t]{2}{*}{ Total } & 39 & 100 & 32 & 100 & 511 & 100 & 382 & 100 & 32 & 100 & 47 & 100 & 10 & 100 & 40 & 100 \\
\hline & \multicolumn{4}{|c|}{$\chi^{2}=2.39 \quad \mathrm{df}=2 ; \mathrm{P}=0.303$} & \multicolumn{4}{|c|}{$\chi^{2}=0.426 \mathrm{df}=2 ; \quad \mathrm{P}=0.808$} & \multicolumn{4}{|c|}{$\chi^{2}=4.945 \mathrm{df}=2 ; \mathrm{P}=0.084$} & \multicolumn{4}{|c|}{$\chi^{2}=6.792 \mathrm{df}=2 ; \mathrm{P}=0.03$} \\
\hline
\end{tabular}

Men were more likely than women to experience family stress regardless of education level. Among men and women with university degree stress was experienced by $29.7 \%$ and $24.1 \%$, respectively $(\chi 2=8492 \mathrm{df}=2 \mathrm{p}=001)$. In those with college degree prevalence of stress was $33.9 \%$ and $19.5 \%$, respectively $(\chi 2=$
$10617 \mathrm{df}=2 \mathrm{p}=0,05)$; in those with a high school education $22.7 \%$ and $15.3 \%$ had family stress, respectively $(\chi 2=6.813 \mathrm{df}=2 \mathrm{p}=0.03)$. Among people with primary level of education men experienced the highest level of stress in the family $(39.3 \%)$ than women $(24.7 \%)(\chi 2=5.946 \mathrm{df}=2 ; \mathrm{p}=0.05)($ Table 7$)$.

Table 7: Family stress and educational level in population 25-64 years (III screening, 1994)

\begin{tabular}{|c|c|c|c|c|c|c|c|c|c|c|c|c|c|c|c|c|}
\hline \multirow{3}{*}{$\begin{array}{l}\text { Family } \\
\text { stress }\end{array}$} & \multicolumn{4}{|c|}{ University } & \multicolumn{4}{|c|}{ College } & \multicolumn{4}{|c|}{ High school } & \multicolumn{4}{|c|}{ Elementary/primary } \\
\hline & \multicolumn{2}{|c|}{ M } & \multicolumn{2}{|c|}{$\mathbf{F}$} & \multicolumn{2}{|c|}{$\mathbf{M}$} & \multicolumn{2}{|c|}{$\mathbf{F}$} & \multicolumn{2}{|c|}{ M } & \multicolumn{2}{|c|}{$\mathbf{F}$} & \multicolumn{2}{|c|}{ M } & \multicolumn{2}{|c|}{$\mathbf{F}$} \\
\hline & $\mathbf{N}$ & $\%$ & $\mathbf{N}$ & $\%$ & $\mathbf{N}$ & $\%$ & $\mathbf{N}$ & $\%$ & $\mathbf{N}$ & $\%$ & $\mathbf{N}$ & $\%$ & $\mathbf{N}$ & $\%$ & $\mathbf{N}$ & $\%$ \\
\hline Low & 28 & 15.4 & 39 & 29.3 & 32 & 18.7 & 47 & 29.6 & 29 & 22.7 & 46 & 37.1 & 19 & 17 & 23 & 28.4 \\
\hline Moderate & 100 & 54.9 & 62 & 46.6 & 81 & 47.4 & 81 & 50.9 & 70 & 54.7 & 59 & 47.6 & 49 & 43.8 & 38 & 46.9 \\
\hline High & 54 & 29.7 & 32 & 24.1 & 58 & 33.9 & 31 & 19.5 & 29 & 22.7 & 19 & 15.3 & 44 & 39.3 & 20 & 24.7 \\
\hline \multirow[t]{2}{*}{ Total } & 182 & 100 & 133 & 100 & 171 & 100 & 159 & 100 & 128 & 100 & 124 & 100 & 112 & 100 & 81 & 100 \\
\hline & \multicolumn{4}{|c|}{$\chi 2=8.492 \mathrm{df}=2 ; \mathrm{P}=0.01$} & \multicolumn{4}{|c|}{$\chi 2=10.617 \mathrm{df}=2 ; \mathrm{P}=0.05$} & \multicolumn{4}{|c|}{$\chi^{2}=6.813 \mathrm{df}=2 ; \mathrm{P}=0.03$} & \multicolumn{4}{|c|}{$\chi 2=5.946 \mathrm{df}=2 ; \mathrm{P}=0.05$} \\
\hline
\end{tabular}

In the studied population, among workers with average physical labor, there were more men (35.9\%) experiencing stress in the family than women $(20.3 \%)(\chi 2=9.736 \mathrm{df}=2 \mathrm{p}=0.008)$. Male pensioners were also reliably more likely to experience stress in the family $(46.9 \%)$ in comparison with females $(23.6 \%)$ belonging to this group $(\chi 2=11.283 \mathrm{df}=2 \mathrm{p}=0.004)$. In other groups, differing in professional level, there was a tendency of increased stress in men, compared with women (Table 8). 


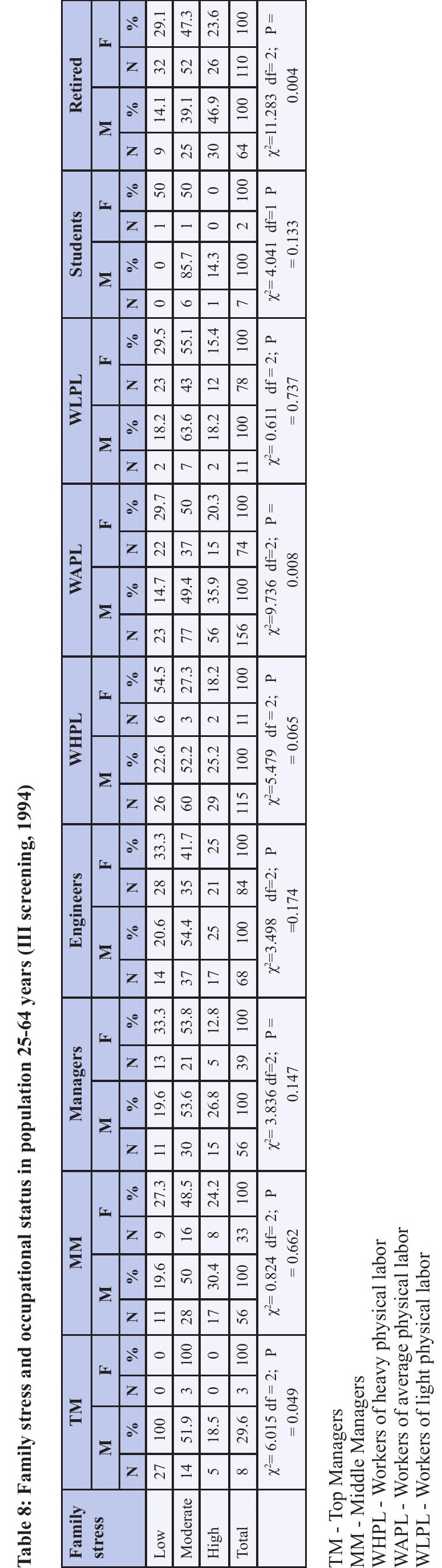


In Cox's univariate regression analysis, the risk of myocardial infarction over a 16-year period among individuals experiencing stress in the family was: among men $\mathrm{HR}=5.9$ (95\% CI 2.54-12.9; $\mathrm{p}<0.001)$ and among women HR $=5.58(95 \%$ CI 1.98-15.7; $\mathrm{p}$ $<0.001$ ) (Table 9).

Table 9: Relative risk of myocardial infarction (Univariate Cox regression model)

\begin{tabular}{|l|l|l|l|l|l|l|l|l|}
\hline \multirow{2}{*}{ Risk Factors } & \multicolumn{4}{|c|}{ male } & \multicolumn{4}{|c|}{ female } \\
\cline { 2 - 9 } & $\mathbf{p}$ & HR & $\mathbf{9 5 . 0 \%}$ CI HR & HR & \multicolumn{9}{|c|}{ 95.0\% CI HR } \\
\hline High \& Moderate family stress & 0.001 & 5.9 & 2.54 & 12.9 & 0.001 & 5.58 & 1.98 & 15.70 \\
\hline
\end{tabular}

In Cox's multivariate regression analysis, the following risk factors were included in the model: stress in the family, as well as social gradient (marital status, educational level and occupational status) and age. The risk of developing myocardial infarction among people with stress in the family compared with those with a low level of stress in the family remained significant for men $\mathrm{HR}=2.3(95 \%$ CI $1.09-5.5 ; \mathrm{p}<0,05)$ and for women $\mathrm{HR}=6.52$
(95\% CI 2.13-19.97; $\mathrm{p}<0.001)$. Living alone is most significant risk factors for myocardial infarction for men compared to married ones. The risk of myocardial infarction among divorced men was 3.9 times higher $(95 \%$ CI 1.2-12.1; $<<0.01)$ and among widowed ones it was 6.3 times higher $(95 \%$ CI $1.3-30,9 ; \mathrm{p}<0.02)$. And MI risk was also higher in retired $\mathrm{HR}=1.7(95 \%$ CI 1.2-2.4; $\mathrm{p}<0.02)$ (Table 10).

Table 10: Relative risk of myocardial infarction (Multivariate Cox Regression Model)

\begin{tabular}{|c|c|c|c|c|c|c|c|c|c|}
\hline \multirow{3}{*}{$\begin{array}{l}\text { Risk Factors } \\
\text { High \& Moderate } \\
\text { family stress }\end{array}$} & \multirow{3}{*}{$\frac{\text { Reference group }}{\text { Low family stress }}$} & \multicolumn{4}{|c|}{ male } & \multicolumn{4}{|c|}{ female } \\
\hline & & \multirow{2}{*}{$\frac{\mathbf{p}}{0.05}$} & \multirow{2}{*}{$\frac{\mathbf{H R}}{2.3}$} & \multicolumn{2}{|c|}{$95.0 \%$ CI HR } & \multirow{2}{*}{$\frac{\mathbf{p}}{0.001}$} & \multirow{2}{*}{$\frac{\text { HR }}{6.52}$} & \multicolumn{2}{|c|}{$95.0 \%$ CI HR } \\
\hline & & & & 1.09 & 5.5 & & & 2.13 & 19.97 \\
\hline $45-64$ years & 25-44 years & 0.1 & 1.5 & 0.5 & 4.5 & 0.52 & 2.12 & 0.20 & 21.82 \\
\hline Never married & \multirow[t]{3}{*}{ Married } & 0.8 & 1.2 & 0.16 & 10.3 & 0.9 & 1.06 & 0.05 & 3.23 \\
\hline Divorced & & 0.01 & 3.9 & 1.2 & 12.1 & 0.67 & 1.15 & 0.02 & 5.63 \\
\hline Widowed & & 0.02 & 6.3 & 1.3 & 30.9 & 0.89 & 1.08 & 0.343 & 3.40 \\
\hline & \multirow[t]{3}{*}{ University } & 0.4 & 1.6 & 0.3 & 6.9 & 0.09 & 2.7 & 0.08 & 9.56 \\
\hline High School & & 0.2 & 2.4 & 0.5 & 11.2 & 0.88 & 1.09 & 0.323 & 3.70 \\
\hline Primary & & 0.07 & 3.3 & 0.9 & 12.7 & 0.50 & 1.22 & 0.03 & 2.95 \\
\hline Physical labor & \multirow[t]{2}{*}{ Managers } & 0.4 & 2.5 & 0.2 & 26.5 & 0.24 & 0.32 & 0.048 & 2.17 \\
\hline Retired & & 0.02 & 1.7 & 1.2 & 2.4 & 0.70 & 0.63 & 0.061 & 6.58 \\
\hline
\end{tabular}

The risk of stroke, as shown by Cox univariate analysis, among those experiencing stress at home was approximately the same compared to those who had lower levels of stress both in men
$\mathrm{HR}=3.45(95 \%$ CI $2.11-7.53 ; \mathrm{p}<0.0001)$ and women $\mathrm{HR}=3.52$ (95\% CI 1.81-6.84; $\mathrm{p}<0.0001)$ (Table 11).

Table 11: Relative risk of stroke (Univariate Cox regression model)

\begin{tabular}{|l|l|l|l|l|l|l|l|l|}
\hline Risk Factors & \multicolumn{2}{|l|}{ male } & \multicolumn{2}{l|}{ female } \\
\hline & $\mathbf{p}$ & HR & $\mathbf{9 5 . 0 \%}$ CI HR & p & HR & \multicolumn{2}{|l|}{ 95.0\% CI HR } \\
\hline High \& Moderate family stress & 0.0001 & 3.45 & 2.11 & 7.53 & 0.0001 & 3.52 & 1.81 & 6.84 \\
\hline
\end{tabular}

Multivariate modeling, including social factors and age in the model, showed that family stress increases the risk of stroke among men by 2.3 times ( $95 \%$ CI 1.9-5.5; $\mathrm{p}<0.05)$ and among women in 3.72 times (95\% CI 1.85-7.5; p <0.001). The risk of stroke was higher in those with high school and primary education compared with those having university degree both in men ( $\mathrm{HR}=3.995 \%$
CI 1.2-12.1; $\mathrm{p}<0.01$ and $\mathrm{HR}=6.395 \%$ CI 1.3-30.9; $\mathrm{p}<0.02$, respectively) and in women ( $\mathrm{HR}=2.8795 \% \mathrm{CI} 1.78-10.61 ; \mathrm{p}<0.03$ and $\mathrm{HR}=3.3395 \% \mathrm{CI} 1.76-14.52 ; \mathrm{p}<0.01$, respectively). The risk of stroke was 1.7 -fold higher among pensioners in comparison with managers in male group (95\% CI 1.2-2.4; $\mathrm{p}<0.02)$ (Table 12). 
Table 12: Relative risk of stroke (Multivariate Cox Regression Model)

\begin{tabular}{|c|c|c|c|c|c|c|c|c|c|}
\hline \multirow{3}{*}{$\begin{array}{l}\text { Risk Factors } \\
\text { High \& Moderate family stress }\end{array}$} & \multirow{3}{*}{$\begin{array}{l}\begin{array}{l}\text { Reference } \\
\text { group }\end{array} \\
\begin{array}{l}\text { Low family } \\
\text { stress }\end{array}\end{array}$} & \multicolumn{4}{|c|}{ male } & \multicolumn{4}{|c|}{ female } \\
\hline & & \multirow{2}{*}{$\begin{array}{c}\mathbf{p} \\
0.05\end{array}$} & \multirow{2}{*}{$\begin{array}{r}\text { HR } \\
2.3\end{array}$} & \multicolumn{2}{|c|}{ 95.0\% CI HR } & \multirow{2}{*}{$\begin{array}{c}\mathbf{p} \\
0.0001\end{array}$} & \multirow{2}{*}{$\begin{array}{l}\text { HR } \\
3.72\end{array}$} & \multicolumn{2}{|c|}{$95.0 \%$ CI HR } \\
\hline & & & & 1.9 & 5.5 & & & 1.85 & 7.50 \\
\hline 55-64 years & $25-54$ years & 0.1 & 1.5 & 0.5 & 4.5 & 0.11 & 3.52 & 0.73 & 16.82 \\
\hline Never married & \multirow[t]{3}{*}{ Married } & 0.4 & 1.6 & 0.3 & 6.9 & 0.82 & 5.46 & 1.23 & 24.28 \\
\hline Divorced & & 0.2 & 2.4 & 0.5 & 11.2 & 0.92 & 0.91 & 0.12 & 6.76 \\
\hline Widowed & & 0.07 & 3.3 & 0.9 & 12.7 & 0.86 & 0.93 & 0.42 & 2.05 \\
\hline College & \multirow[t]{4}{*}{ University } & 0.8 & 1.2 & 0.16 & 10.3 & 0.14 & 2.44 & 0.74 & 8.03 \\
\hline High School & & 0.01 & 3.9 & 1.2 & 12.1 & 0.03 & 2.87 & 1.78 & 10.61 \\
\hline Primary & & 0.02 & 6.3 & 1.3 & 30.9 & 0.01 & 3.33 & 1.76 & 14.52 \\
\hline Workers of heavy physical labor & & 0.9 & 4.6 & 0.4 & 46.3 & 0.82 & 1.18 & 0.04 & 5.83 \\
\hline $\begin{array}{l}\text { Workers of average physical } \\
\text { labor }\end{array}$ & \multirow[t]{2}{*}{ Managers } & 0.4 & 2.5 & 0.2 & 26.5 & 0.74 & 1.16 & 0.46 & 2.90 \\
\hline Retired & & 0.02 & 1.7 & 1.2 & 2.4 & 0.54 & 1.56 & 0.37 & 6.63 \\
\hline
\end{tabular}

\section{Discussion}

The concept that family stress can be associated with coronary heart disease (CHD) has existed since the late 1970s, beginning with the pioneering work of Medalie and Goldbourt in 1976 [14]. To date, most research on family problems and their health effects has focused on feelings of happiness and satisfaction in the family. Interpersonal responses to conflict as well as the impact of spousal work outside the home are new concepts in predicting the health outcomes of family stress. For example, some criteria of stress in the family are very often used to form a conceptual understanding of family well-being: a) family happiness and satisfaction; b) the number and type of disagreements; c) the feelings of people in marriage, which reflects the level of interaction between spouses. Of greatest interest are other parameters: d) how a person reacts to a conflict with a spouse, which reflects an interpersonal response to stress, and e) the influence of a spouse's work, which shows how the spouse's external activities affect married life [15].

In our study, we analyzed both the external activities of the spouses (indicators of the level of education and professional activity) and marital status, and their impact on the level of stress in the family. In the studied working-age population men (31.5\%) more often experienced a high level of stress in the family than women $(20.9 \%)$. The prevalence of stress was higher in middleaged women $(22.9 \%)$ while it was higher in older male $(39.3 \%)$. The highest level of stress in the family was observed among widowed men (30\%) and women (22.5\%). The death of a husband or wife is one of the most severe stressors. For example, according to the Holmes - Rahe comparative scale, the death of a spouse is estimated at a maximum of 100 points on the scale [16]. The loss of spouse played the most significant role in the risk of myocardial infarction in men which increased more than 6 times and the risk of myocardial infarction increased almost 4 times among divorced men. Our results are consistent with the Framingheim study, which showed that married men have a survival advantage compared to unmarried men [15]. In a study of middle-aged men in the Netherlands unmarried men had a significantly higher risk of all-cause death $(\mathrm{HR}=1.7)$ and coronary mortality $(\mathrm{HR}=2.2)$ than married men [17]. In a Finnish study unmarried men had significantly higher mortality rates compared with married men [18].

The highest level of stress in the family (39.3\%) was experienced by men with primary educational level as well as those related to workers with average physical labor (35.9\%). In our population a low level of education contributed to an increased risk of stroke in both men $(\mathrm{HR}=6.3)$ and women $(\mathrm{HR}=3.33)$. Our findings are consistent with a cohort study in Australia where low educational attainment was associated with an increased risk of stroke in both men and women [19].

We did not find significant differences in groups experiencing stress in the family and differing by gender over 16 years of follow-up. The risk of myocardial infarction in men and women was almost 6 times higher and the risk of stroke was 3.5 times higher.

In the past 5-10 years, many datasets have been pooled in 'metaanalyzes', which has greatly accelerated progress in research on stress as a predictor of CVD risk. Severe stressful experiences in childhood such as physical violence and substance abuse in the family can be harmful to health and increase the risk of multiple chronic conditions in adulthood. Compared to childhood stress and classic adult risk factors such as smoking, high blood pressure and high serum cholesterol, the harmful effects of stress in adulthood are generally less pronounced. However, stress in adulthood plays an important role as a disease trigger in people who already have high levels of atherosclerotic plaques and as a determinant of prognosis and outcome in people with pre-existing cardiovascular or cerebrovascular disease. Longitudinal studies support earlier laboratory stress related observations concerned pathophysiological alterations. The decrease in the arrhythmic threshold and sympathetic activation with a corresponding increase in blood pressure as well as pro-inflammatory and procoagulant 
reactions are precursors of mental stress. In some clinical guidelines, stress has already been recognized as a prevention goal for people with a high overall risk of cardiovascular disease or with established cardiovascular disease [20].

\section{Conclusions}

1. In the open population of 25-64 years in Novosibirsk family stress was higher among men (31.5\%) compared to women $20.9 \%$. High level of stress were more common among men aged of 55-64 years (39.3\%) and women aged of 45-54 years $(22.9 \%)$.

2. The highest level of family stress in our population was experienced by widowed men (30\%) and women $(22.5 \%)$; persons with primary level of education: men - 39.3\%, women - $24.7 \%$; workers of average physical labor: men - $35.9 \%$, women $-20.3 \%$.

3. The risk of myocardial infarction over a 16 -year period in persons experiencing family stress was among men $\mathrm{HR}=5.9$ and among women $\mathrm{HR}=5.58$. The most significant risk factors for myocardial infarction incidence were divorcing $(\mathrm{HR}=3.9)$ and widowhood $(\mathrm{HR}=6.3)$.

4. The risk of stroke in men with family stress 3.45-fold higher and in women 3.52-fold higher. The risk of stroke was higher in those with high school and primary education both in men $(\mathrm{HR}=3.9$ and $\mathrm{HR}=6.3)$ and women $(\mathrm{HR}=2.87$ and $\mathrm{HR}=3.33)$.

The work was performed within the framework of the budgetary theme NIITPM - branch of the ICG SB RAS Reg. № AAAA-A17-117112850280-2, Gov.Task № 0324-2018-0001

\section{References}

1. GBD 2013 Mortality and Causes of Death Collaborators (2015) Global, regional, and national age-sex specific allcause and cause-specific mortality for 240 causes of death, 1990-2013: a systematic analysis for the Global Burden of Disease Study 2013. Lancet 385: 117-171.

2. Wong CW, Kwok CS, Narain A, Gulati M, Mihalidou AS, et al. (2018) Marital status and risk of cardiovascular diseases: a systematic review and meta-analysis. Heart 104: 1937-1948.

3. Xie G, Zou H, Myint PK, Shi P, Ren F, et al. (2016) Baseline overall health-related quality of life predicts the 10-year incidence of cardiovascular events in a Chinese population. Qual Life Res 25: 363-371.

4. Satyjeet FNU, Naz S, Kumar V, Aung NH, Bansari K, et al. (2020) Psychological Stress as a Risk Factor for Cardiovascular Disease: A Case-Control Study. Cureus 12: e10757.

5. Consuegra-Sanchez L, Melgarejo-Moreno A, Jaulent-Huertas L, Díaz-Pastor Á, Escudero-García G, et al. (2015) Unraveling the relations between marital status and prognosis among myocardial infarction survivors: impact of being widowed on mortality. Int J Cardiol 185: 141-143.

6. Vujcic I, Vlajinac H, Dubljanin E, Vasiljevic Z, Matanovic D, et al. (2015) Long-term prognostic significance of living alone and other risk factors in patients with acute myocardial infarction. Ir J Med Sci 184: 153-158.

7. Andersen KK, Andersen ZJ, Olsen TS (2011) Predictors of early and late case-fatality in a nationwide Danish study of 26,818 patients with first-ever ischemic stroke. Stroke 42: 2806-2812.

8. Floud S, Balkwill A, Canoy D (2014) Marital status and ischemic heart disease incidenceand mortality in women: a large prospective study. BMC Med 12: 42.

9. Kriegbaum M, Christensen U, Lund R, Prescott E, Osler M (2008) Job loss and broken partnerships: do the number of stressful life events influence the risk of ischemic heart disease in men? Ann Epidemiol 18: 743-745.

10. Kilpi F, Konttinen H, Silventoinen K, Martikainen P (2015) Living arrangements as determinants of myocardial infarction incidence and survival: a prospective register study of over 300,000 Finnish men and women. Soc Sci Med 133: 93-100.

11. MONICA Monograph and Multimedia Sourcebook. Helsinki: 2003: 237.

12. Nasledov AD (2013) IBM SPSS 20 Statistics and AMOS: Professional Statistical Data Analysis. A practical guide. SPb.: Peter. (In Russ.)

13. Cox DR (1972) Regression Models and Life Tables. Journal of the Royal Statistical Society Series B.; 34: 187-220.

14. Medalie JH, Goldbourt U (1976) Angina pectoris among 10,000 men. II. Psychosocial and other risk factors as evidenced by a multivariate analysis of a five-year incidence study. Am J Med 60: 910-921.

15. Eaker ED, Sullivan LM, Kelly-Hayes M, D'Agostino RB Sr, Benjamin EJ (2007) Marital status, marital strain, and risk of coronary heart disease or total mortality: The Framingham Offspring Study. Psychosomatic Medicine 69: 509-513.

16. Noone PA (2017) The Holmes-Rahe Stress Inventory. Occupational Medicine 67: 581-582.

17. Mendes de Leon CF, Appels AW, Otten FW, Schouten EG (1992) Risk of mortality and coronary heart disease by marital status in middle-aged men in the Netherlands. Int J Epidemiol 21: 460-466.

18. Valkonen T (1982) Psychosocial stress and sociodemographic differentials in mortality from ischaemic heart disease in Finland. Acta Med Scand Suppl 660: 152-164.

19. Jackson CA, Sudlow CLM, Mishra GD (2018) Education, sex and riskof stroke: a prospective cohort study in New SouthWales, Australia. BMJ Open 8: e024070.

20. Dhindsa DS, Khambhati J, Schultz WM, Tahhan AS, Quyyumi AA (2020) Marital status and outcomes in patients with cardiovascular disease. Trends Cardiovasc Med 30: 215-220.
Copyright: (2021 Valery V Gafarov, et al. This is an open-access article distributed under the terms of the Creative Commons Attribution License, which permits unrestricted use, distribution, and reproduction in any medium, provided the original author and source are credited. 